pneumoniae: case report and review. Clin Infect Dis, 25 (5), 1108-12.

5. Hafidh M. A., Keogh I., Walsh R. M., Walsh M., Rawluk D. (2006), Otogenic intracranial complications. a 7-year retrospective review. Am J Otolaryngol, 27 (6), 390-5.

6. Ionita C., Wasay M., Balos L., Bakshi R. (2004), MR imaging in toxoplasmosis encephalitis after bone marrow transplantation: paucity of enhancement despite fulminant disease. AJNR Am J Neuroradiol, 25 (2), 270-3.

7. Lu C. H., Chang W. N., Lin Y. C., Tsai N. W. Liliang P. C., Su T. M., Rau C. S., Tsai Y. D.,
Liang C. L., Chang C. J., Lee P. Y., Chang H. W., Wu J. J. (2002), Bacterial brain abscess: microbiological features, epidemiological trends and therapeutic outcomes. Qjm, 95 (8), 501-9.

8. Osma U., Cureoglu S., Hosoglu S. (2000), The complications of chronic otitis media: report of 93 cases. J Laryngol Otol, 114 (2), 97-100.

9. Sennaroglu L., Sozeri B. (2000), Otogenic brain abscess: review of 41 cases. Otolaryngol Head Neck Surg, 123 (6), 751-5.

10. Tonon E., Scotton P. G., Gallucci M., Vaglia A. (2006), Brain abscess: clinical aspects of 100 patients. Int J Infect Dis, 10 (2), 103-9.

\title{
THỰC TRANG TRẦM CẢM CỦA NGƯỜI NHIỄM HIV/AIDS ĐANG ĐÎ̂̀U TRI ARV TẠI 2 PHÒNG KHÁM NGOẠI TRÚ TỈNH THÁI BÌNH
}

\section{TÓM TẮT}

Mục tiêu: Mô tả thực trạng trâm cảm của người nhiểm HIV/AIDS đang điều trị ARV tại 2 phòng khám ngoại trú tỉnh Thái Bình năm 2019. Đối tượng nghiên cứu: bệnh nhân HIV/AIDS người lớn $\geq 18$ tuổi đang điều trị ARV. Phương pháp nghiên cứu: Phương pháp mô tả thông qua cuộc điêu tra cắt ngang. Kết quả nghiên cứu: Tỷ lệ trầm cảm ở người bệnh điều trị ARV là $36,3 \%$. Người bệnh nam có tỷ lệ trầm cảm thấp hơn người bênh nữ $(35,5 \%$ và $37,3 \%$, $p>0,05)$, nhóm tuổi có tỷ lệ trâm cảm cao nhất là tứ 50 tuổi trở lên $(75,4 \%)$, tỷ lệ thấp nhất ở nhóm 30-39 tuổi chiếm 18,6\%. Trong số những người bệnh ARV $82,8 \%$ người thất nghiệp; $65,8 \%$ nông dân; $26,1 \%$ người làm lao động tự do có dấu hiệu trầm cảm. $59,5 \%$ những người nhiễm HIV/AIDS sử dụng ma túy có dấu hiệu trầm cảm.

Tư khóa: Trầm cảm; HIV/AIDS; Thái Bình.

\section{SUMMARY \\ DEPRESSION SITUATION OF HIV/AIDS PATIENTS WHO TREATED HIV/AIDS WITH ARV AT 2 OUTPATIENT CLINICS IN THAI BINH PROVINCE}

Objectives: Describe the depression situation of HIV / AIDS patients who treated HIV/AIDS with ARV at 2 outpatient clinics in Thai Binh province in 2019. Subjects: HIV / AIDS patients adults $\geq 18$ years old being treated with ARV. Method: Descriptive method through cross-sectional survey. Results: The prevalence of depression in HIV patients was 36,3\%. Male patients had a lower rate of depression than female patients $(35,5 \%$ and $37,3 \%, p>0.05)$. Patients

\footnotetext{
${ }^{1}$ Trường Đại hoc Y Dược Thái Bình

${ }^{2}$ Trung tâm kiểm soát bênh tất tỉnh Thái Bình

Chịu trách nhiệm chính: Ngô Văn Mạnh

Email: manhsdh@gmail.com

Ngày nhận bài: 22.6.2021

Ngày phản biên khoa họ: 23.8.2021

Ngày duyệt bài: 30.8.2021
}

Ngô Văn Mạnh ${ }^{1}$, Bùi Thị Hồng Vân ${ }^{2}$

50 years of age and older had the highest rates of depression, the lowest rate in the group of 30-39 years old accounted for $18.6 \%$. Among patients, $82,8 \%$ were unemployed; $65,8 \%$ of farmers; $26,1 \%$ of self-employed workers showed signs of depression $(p<0,05) ; 59,5 \%$ of HIV patient used drug had signs of depression.

Keywords: Depression; HIV/AIDS; Thai Binh

\section{I. ĐĂT VẤN ĐỀ}

HIV là một bênh lây nhiễm đai dich có tác động tới xã hội lớn nhất từ trước đến nay. Bệnh gẩy suy giảm miê̂n dịch và nhạy cảm với một loạt các loại nhiễm trùng cơ hội và nhiễm trùng khác cũng như sự phát triển của các bệnh ác tính nhất định [1]. Cùng với sự điêu trị nhằm ức chế sự sản sinh của virus HIV bằng thuốc $A R V$ và điều trị các bênh thực thể liên quan đến HIV, người bệnh HIV cũng được chăm sóc, hỗ trợ nhằm tăng cường sức khỏe thể chất. Tuy nhiên, khi sức khỏe thể chất được đảm bảo thì sức khỏe tâm thân của người nhiễm HIV cũng là một trong những vấn đề cân được quan tâm và can thiệp nhằm nâng cao hiệu quả điêuu trị cho họ. Người bệnh nhiểm HIV có thể gặp phải những ảnh hưởng tâm lý xã hội, các vấn đề sức khỏe tâm thân bắt đầu từ rất sớm ngay khi có chẩn đoán ban đâu và có thể phát sinh trong cả thời gian điều trị bệnh. Các vấn đề phổ biến thường gặp phải là trấm cảm, lo âu và làm dụng các chất gây nghiện. Trong đó, trâm cảm là biến chứng thân kinh phổ biến nhất ở bệnh nhân nhiễm HIV và hạn chế đáng kể chất lượng cuộc sống của bệnh nhân HIV/AIDS [8].

Các nghiên cứu trên thế giới cũng cho thấy việc điều trị những người bệnh trầm cảm cũng thực sự khó khăn nếu như họ không tự nhận thức được vấn đề họ gặp phải. Các nhà nghiến 
cứu đã chỉ ra rằng nhận thức thấp về bênh không những liên quan đến việc bệnh nhân trầm cảm không đến cơ sở chăm sóc y tế cho đến khi bệnh kéo dài, trở nên trầm trọng hơn [9] mà còn ảnh hưởng lớn đối với việc tìm kiếm sự giúp đõ và cam kết với những can thiệp được đề nghị và cả phòng ngừa [10].

Tại Việt Nam, các nghiên cứu đánh giá về tỷ lệ trầm cảm ở người bệnh nhiễm HIV đã được triển khai tại một số tỉnh nhưng hầu hết là các tỉnh thành lớn. Vì vậy chúng tôi tiến hành nghiên cứu đề tài với mục tiêu: Mô tả thực trạng mắc trầm cảm ở người nhiếm HIV/AIDS đang điều trị ARV tại 2 phòng khám ngoại trú tỉnh Thái Bình năm 2019.

\section{II. ĐỐI TƯợNG VÀ PHƯƠNG PHÁP NGHIÊN CỨU 2.1. Địa điểm, thời gian, đối tượng nghiên cứu}

- Địa điểm nghiên cứu: 02 phòng khám ngoại trú gồm: Phòng khám ngoại trú Bệnh viện Đa khoa thành phố Thái Bình và Phòng khám ngoại trú Bệnh viện Đa khoa huyện Kiến Xương

- Đối tượng nghiên cứu: Là bệnh nhân HIV/ AIDS người lớn $\geq 18$ tuổi (gọi tắt là người bệnh) đang điêu trị ARV tại 2 phòng khám nghiên cứu.

- Thời gian nghiên cứu: Nghiên cứu được thực hiện từ 10/2019 - 5/2020

\subsection{Phương pháp nghiên cứu}

2.2.1. Thiết kế nghiên cứu. Nghiên cứu mô tả thông qua cuộc điều tra cắt ngang.

\subsubsection{Cỡ mẫu và phương pháp chọn mẫu}

\section{a/ Cõ̃ mẫu}

Áp dụng công thức tính cỡ mẫu cho ước lượng một tỷ lệ:

$$
n=Z_{1-\alpha / 2}^{2} \frac{p \cdot(1-p)}{d^{2}}
$$

Với $Z=1,96 ; p=0,392$ (Theo nghiên cứu của Phạm Đình Quyết năm 2017, tỷ lệ người nhiếm HIV/AIDS mắc trầm cảm tại PKNT Gò Vấp là $39,2 \%$ [5]; $d=0,05$; Với các dữ liệu trên tính được $n=366$ bệnh nhân

Thực tế điều tra được 386 người bệnh đang điều trị ARV.

b/ Phương pháp chơn mẫu: Tiến hành chọn chủ đích 02 phòng khám ngoại trú tại Bệnh viện Đa khoa Thành phố Thái Bình và Bệnh viện Đa khoa huyện Kiến Xương.

Tiến hành điều tra toàn bộ bệnh nhân điều trị tại 2 phòng khám đã chọn tại thời điểm nghiên cứu. Thực tế tổng 2 phòng khám có 386 bệnh nhân đang đăng ký điều trị

2.3. Phương pháp thu thập thông tin. Thông tin thu thập qua hồ sơ, bệnh án gồm các thông tin về tuân thủ điều trị, kết quả xét nghiệm T-CD4 lần gần nhất, tác dụng phụ của thuốc, bệnh lâm sàng kèm theo, giai đoạn lâm sàng hiện tại. Thông tin định lượng được thu thập thông qua: phiếu phỏng vấn trực tiếp người nhiếm HIV/AIDS đang điêu trị ARV tại địa bàn nghiên cứu được chọn để xác định tỷ lệ trâm cảm

2.4. Các tiêu chuẩn sử dụng trong nghiên cứu. Đánh giá trầm cảm sử dụng thang đo Center for epidemiologic study depression scale (CES-D):

+ Trong từng câu hỏi, dấu hiêu hành vi được coi là "Có" nếu xuất hiện với tần suất từ "Đôi khi" đến "Rất hay xảy ra".

+ Phân loại dấu hiệu trầm cảm dựa theo tổng điểm của bô câu hỏi CES-D20: Tổng điểm <16: không có dấu hiệu trầm cảm. Tổng điểm $\geq 16$ : có dấu hiệu trầm cảm.

2.5. Xử lý số liệu. Số liệu sau khi điều tra được làm sạch thô và nhập vào máy vi tính bằng phần mềm EPI-DATA, sau đó chuyển sang phần mềm SPSS 20.0 để xử lý với các test thống kê y học.

\section{KẾT QUẢ NGHIÊN CứU}

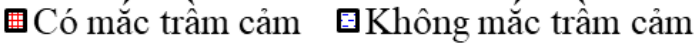

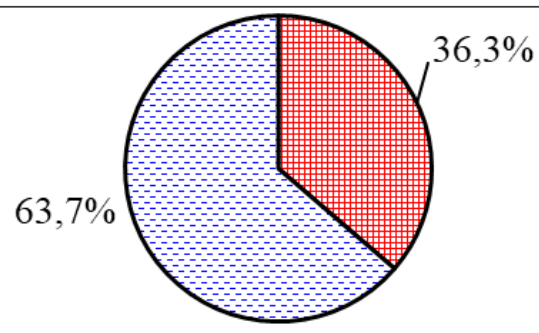

\section{Biểu đồ 3.1. Tỷ lệ mắc trâm cảm của đôi} tương nghiên cứu $(n=386)$

Trong tổng số 386 bệnh nhân đang điều trị ARV được đưa vào nghiên cứu có 140 bệnh nhân có dấu hiệu trầm cảm chiếm $36,3 \%$.

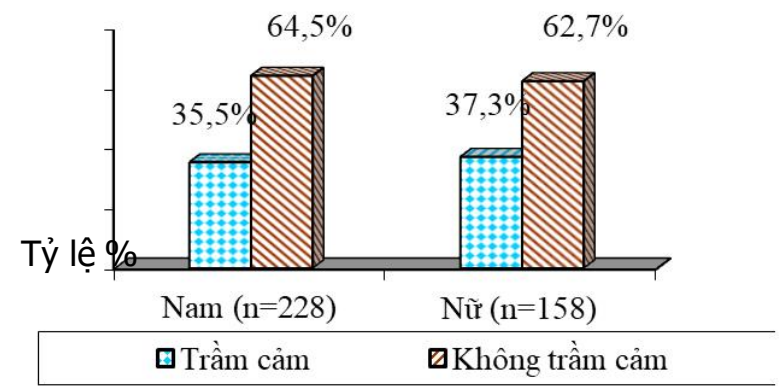

Biểu đồ 3.2. Tỷ lệ mắc trâm cảm của đôi tượng theo giới $(n=386)$ 
Kết quả biểu đồ 3.2 cho thây, tỷ lệ nam giới mắc trâm cảm là $35,5 \%$, nữ giới là $37,3 \%$. Sự khác biệt không có ý nghĩa thống kê với p>0,05

Bảng 3.1. Tỷ lệ mắc trâm cảm của đôí tương theo nhóm tuổi $(n=386)$

\begin{tabular}{|c|c|c|c|c|}
\hline $\begin{array}{l}\text { Nhóm } \\
\text { tuổi }\end{array}$ & $\begin{array}{c}\text { Số điêuu } \\
\text { tra }\end{array}$ & $\begin{array}{c}\text { Số } \\
\text { lươong }\end{array}$ & $\begin{array}{l}\text { Tỷ lệ } \\
(\%)\end{array}$ & $\mathbf{p}$ \\
\hline $18-29$ & 15 & 4 & 26,7 & \multirow{4}{*}{$\begin{array}{l}<0 \\
05\end{array}$} \\
\hline $30-39$ & 118 & 22 & 18,6 & \\
\hline $40-49$ & 196 & 71 & 36,2 & \\
\hline$\geq 50$ & 57 & 43 & 75,4 & \\
\hline
\end{tabular}

Bảng 3.1 cho thấy nhóm tuổi từ 50 tuổi trở lên có tỷ lệ mắc trầm cảm cao nhất $(75,4 \%)$, tiếp đó là nhóm tuổi 40-49 là 36,2\%, nhóm tuối 18 - 29 tuổi có tỷ lệ trâm cảm chiếm 26,7\%; tỷ lệ trâm cảm gặp ở nhóm tuổi từ 30-39 là thấp nhất (18,6\%). Sự khác biệt có ý nghĩa thống kê với $p<0,05$

Bảng 3.2. Tỷ lê mắc trâm cảm của đôî tượng theo nghề nghiêp ( $n=386)$

\begin{tabular}{|c|c|c|c|c|}
\hline Nghề nghiệp & $\begin{array}{c}\text { Số đîều } \\
\text { tra }\end{array}$ & $\begin{array}{c}\text { Số } \\
\text { lướng }\end{array}$ & $\begin{array}{c}\text { Tỷ lệ } \\
\text { \% }\end{array}$ & $\mathbf{p}$ \\
\hline Nông dân & 73 & 48 & 65,8 & \multirow{6}{*}{$\begin{array}{l}<0 \\
05\end{array}$} \\
\hline Công nhân & 59 & 5 & 8,5 & \\
\hline Công chức/Viên chức & 5 & 4 & 80,0 & \\
\hline Thất nghiệp & 29 & 24 & 82,8 & \\
\hline Học sinh/Sinh viên & 2 & 2 & 100 & \\
\hline Lao động tự do & 218 & 57 & 26,1 & \\
\hline
\end{tabular}

Bảng 3.3. Tỷ lệ mắc trâm cảm theo số năm điều trị ARV và đường lây nhiễm HIV $(n=386)$

\begin{tabular}{|c|c|c|c|c|c|}
\hline Biến số & Yếu tố & $\begin{array}{c}\text { Số điêêu } \\
\text { tra }\end{array}$ & $\begin{array}{l}\text { Số lượng } \\
(\mathrm{n}=386)\end{array}$ & $\begin{array}{l}\text { Tỷ lệ } \\
(\%)\end{array}$ & $\mathbf{p}$ \\
\hline \multirow{2}{*}{ Số năm điều trị } & Điều trị $\leq 5$ năm & 80 & 29 & 36,2 & \multirow{2}{*}{$>0,05$} \\
\hline & Điều trị > 5 năm & 306 & 111 & 36,3 & \\
\hline \multirow{3}{*}{ Đường lây } & Lây qua đường máu & 96 & 36 & 37,5 & \multirow{3}{*}{$>0,05$} \\
\hline & Lây qua đường tình dục & 233 & 86 & 36,9 & \\
\hline & Không rõ đường lây & 57 & 18 & 31,6 & \\
\hline
\end{tabular}

Bảng 3.3 cho thấy tỷ lệ bệnh nhân điều trị trên 5 năm có dấu hiệu trầm cảm chiếm $36,2 \%$; tỷ lệ ĐTNC điều trị từ 5 năm trở xuống bị trầm cảm chiếm $36,3 \%$. Trong nhóm người bệnh lây nhiễm HIV qua quan hệ tình dục có $36,9 \%$ mắc trầm cảm; lây qua đường máu có $37,5 \%$ người mắc trầm cảm và không rõ đường lây truyền có $31,6 \%$ mắc trầm cảm.

Bảng 3.4. Tỷ lệ mắc trâm cảm của đôi tượng theo thu nhập hàng tháng (n=386)

\begin{tabular}{|c|c|c|c|c|}
\hline Thu nhập & Số điêuu tra & $\begin{array}{l}\text { Số lượng } \\
(n=386)\end{array}$ & $\begin{array}{l}\text { Tỷ lề } \\
\text { ( } \%)\end{array}$ & $\mathbf{p}$ \\
\hline$<1$ triệu & 65 & 47 & 72,3 & \multirow{5}{*}{$<0,05$} \\
\hline 1 đến < 3 triệu & 107 & 61 & 57,0 & \\
\hline 3 đến < 5 triệu & 113 & 19 & 16,8 & \\
\hline 5 đến < 8 triệu & 90 & 11 & 12,2 & \\
\hline$\geq 8$ triệu & 11 & 2 & 18,2 & \\
\hline
\end{tabular}

Kết quả bảng 3.4 cho thẫy nhóm đối tượng có mức thu nhập dưới 1 triệu đồng có tỷ lệ mắc trâm cảm cao nhất (72,3\%), sau đó đến nhóm từ 1 - dưới 3triêuu đồng (57\%). Các nhóm 3 - dưới 5 triệu có $16,8 \%$; nhóm từ 5 - dưới 8 triệu là $12,2 \%$ và nhóm từ 8 triệu trở lên là $18,2 \%$ bị trầm cảm. Sự khác biệt có ý nghĩa thống kê với pie0,05 
VIETNAM MEDICAL JOURNAL N²2 - SEPTEMBER - 2021

Bảng 3.5. Tỷ lê mắc tràm cảm của đôi tương nghiên cứu theo hành vỉ sử dung ma túy

\begin{tabular}{|c|c|c|c|c|}
\hline Sứ dụng ma túy & Số điều tra & Số lượng $(n=386)$ & Tỷ lệ \% \% & P \\
\hline Có sự dụng ma túy & 42 & 25 & 59,5 & \multirow{2}{*}{$<0,05$} \\
\hline Không sự dụng ma túy & 344 & 115 & 33,4 & \\
\hline
\end{tabular}

Bảng 3.5 cho thấy: tỷ lệ trầm cảm ở nhóm không sử dụng ma túy chiếm 33,4\%, nhóm có sử dụng ma túy $59,5 \%$. Sự khác biệt có ý nghĩa thống kê với $p<0,05$

\section{BÀN LUÂNN}

Nghiên cứu này của chúng tôi là nghiên cứu đầu tiên đánh giá về rối loạn trầm cảm ở người nhiễm HIV đang điều trị ARV được thực hiện tại Thái Bình. Kết quả thu được trong số 386 đối tượng nghiên cứu, qua phỏng vấn bằng thang đánh giá trầm cảm CES-D chúng tôi phát hiện có 140 ĐTNC có dấu hiệu trầm cảm, chiếm tỷ lệ $36,3 \%$. Tỷ lệ này tương đồng với tỳ lệ trầm cảm trong nghiên cứu của Pham Đình Quyết là 39,2\% [5] và một số nghiên cứu khác, $40 \%$ ĐTNC có dấu hiệu trầm cảm trong nghiên cứu của Green [7]. Kết quả này cho tỷ lệ trầm cảm trong nhóm bệnh nhân đang điều trị ARV cao hơn nhiều lần so với tỷ lệ trâm cảm chung của cộng đồng trên toàn câu là $4,4 \%$, tại Việt Nam là $4 \%$ theo báo cáo của WHO năm 2017 [11]. Điều này cho thấy viêc cần thiết phải thường xuyên sàng loc các triệu chứng trầm cảm và giời thiệu tới các cơ sở chằm sóc sức khỏe tâm thân cho bệnh nhân ARV tại các cơ sở điều trị HIV/AIDS nhằm làm giảm tác hại của bệnh gây ra.

Tỳ lệ trầm cảm trong nghiên cứu này thấp hơn hẳn so với tỷ lệ trầm cảm sau sinh ở nhóm phụ nữ nhiễm HIV tại nghiên cứu của Nguyễn Manh Hoan năm 2016 là 61,8\% [4]. Có sư khác biệt này là do nghiên cứu của tác giả chỉ thực hiện trên nhóm phụ nữ nhiếm HIV. Nghiên cứu này cũng chỉ ra rằng nhóm phụ nữ nhiểm HIV có nguy cơ mắc trầm cảm sau sinh cao hơn 5 lần so với phụ nữ không nhiễm HIV. Rất tiếc trong nghiên cứu của chúng tôi không có sự xuất hiện của đối tượng nghiên cứu là phụ nữ sau sinh nền không có sự đánh giá về tỷ lệ mắc trầm cảm của nhóm bệnh nhân này. Tuy nhiên, đây cũng là một điểm cần lưu ý đối với các cơ sở điều trị để chú ý sàng lọc đánh giá trầm cảm đối với các sản phụ nhiễm HIV khi họ tái khám.

ở nhóm nam giới nhiễm HIV, nghiên cứu của tác giả Catherine Anne Esposito tại 2 thành phố Hà Nội và Thành phố Hồ Chí Minh cho kết quả chỉ có $18,7 \%$ đối tượng nghiên cứu có dấu hiệu trầm cảm [6]. Tỷ lệ này cao hơn tỷ lệ trầm cảm ở nam giới Việt Nam nói chung $(0,9 \%)$ nhưng thấp hơn nhiều so với kết quả nghiên cứu của chúng tôi cũng như nghiên cứu của Nguyễn Mạnh Hoan phía trên. Cũng dễ hiểu do nghiên cứu này chỉ thực hiện trên nhóm đối tượng bệnh nhân là nam giới, mà trên thực tế nhiều nghiên cứu và báo cáo trước đây cũng đã chỉ ra tỷ lệ nữ giới mắc trầm cảm phổ biến hơn ở nam giới [11] do nữ giới luôn luôn lo lắng về bệnh tật, sức chịu đựng kém, gánh nặng chăm sóc gia đình, con cái; và một vài yếu tố quan trọng không kém đó là do nôi tiết tố chi phối như tiền mãn kinh, mãn kinh khiến cho tỷ lệ trầm cảm của nữ giới luôn có xu hướng cao hơn nam giới.

Về giới tính, trong 140 bệnh nhân có dấu hiệu trầm cảm có $57,9 \%$ số đó là nam giới còn lại 42,15 là nữ giới. Nếu chỉ xét theo tỷ lệ này ta sẽ thấy số lượng nam giới trầm cảm nhiều hơn nữ giới. Tuy nhiên, khi xét tỷ lệ trầm theo giới thì nữ giới có $59 / 158$ bệnh nhân nữ có triệu chứng trầm cảm chiếm $37,3 \%$ cao hơn so với $81 / 228$ bệnh nhân nam có triệu chứng trầm cảm $(35,5 \%)$. Kết quả này phù hợp với tỳ lệ mắc theo giới của cộng đồng nói chung và hầu hết các nghiên cứu trên nhóm bệnh nhân HIV nói riêng. Tác giả Nguyễn Thanh Cao trong Luận án chuyên khoa cấp II của mình khi nghiên cứu về trầm cảm ở người trưởng thành cũng chỉ ra tỷ lệ nữ giới mắc trầm cảm $(8,3 \%)$ cao hơn ở nam giới chỉ có 1,6\% [2].

Trong các nghiên cứu về trầm cảm ở người bệnh HIV, tỷ lệ nữ giới mắc trầm cảm cũng cao hớn nam giới tại nghiên cứu của Trương Thị Hòa [3]. Điều này như đã được lý giải ở trên, nguyên nhân là do phụ nữ thường xuyên lo lắng về sức khỏe, bệnh tật của mình, kèm theo đó là sự ảnh hưởng nội tiểt tố trong các giai đoạn tuổi tác và cơ thể gây ra. Tuy nhiên, các kết quả về sự chênh lệch tỷ lệ này cùng với kết quả trong nghiên cứu của chúng tôi không có sự khác biệt có ý nghĩa thống kê.

Về nhóm tuổi, nghiên cứu của chúng tôi cho tỷ lệ mắc trầm cảm cao nhất ở nhóm tuổi 50 tuổi trở lên với $75,4 \%$. Kết quả này có sự tương đồng với nghiên cứu của Nguyễn Thanh Cao khi nghiên cứu về thực trang trầm cảm trong cộng đồng tại Bắc Kạn với tỳ lệ mắc trầm cảm cao gặp ở các nhóm tuổi từ 51 tuổi trở lên [2]. Tuy nhiển nó lại khác biệt khi so sánh với các nghiên của Trưởng Thị Hòa, độ tuổi mắc trầm cảm chủ yếu là dưới 35 tuổi chiếm 35,89\% [3]. Có thể sự khác biệt này do nghiên cứu của tác giả trên 
thực hiện tại các tỉnh phía Nam dẫn đến sự khác biệt về mổ hình trầm cảm theo nhóm tuổi là khác nhau. Bên cạnh đó, tỷ lệ trầm cảm tăng cao theo nhóm tuổi cũng phù hợp với mô hình trầm cảm chung trong cộng đồng. Hơn nữa, ở những người trẻ tuổi đã điều trị thời gian dài, họ có nhiều bận tâm về công việc và dễ bỏ qua cái nhìn của người xung quanh hơn so với những người bệnh lớn tuối, nhiều thời gian rảnh, dề mắc bệnh khác và dễ ảnh hưởng tâm lý hơn. Trong nghiên cứu này sự khác biệt về tỷ lệ trầm cảm giữa các nhóm tuổi là sự khác biệt có ý nghĩa thống kê.

Kết quả nghiên cứu của chúng tôi cũng cho thây những người bệnh có thu nhập thấp dưới 1 triệu đồng/tháng và từ 1 -3triệu/tháng hay những người có công việc không ổn định như nông dân, những người thất nghiệp có tỳ lệ mắc trâm cảm cao hơn những nhóm còn lại. Tỷ lệ trâm cảm ở các nhóm này lần lượt là $72,3 \%$, $57 \%, 65,8 \%, 82,8 \%$. Cũng dễ hiểu tại sao có tý lệ như vậy là do người bệnh công việc không ổn định, tỷ lệ thất nghiệp cao, người có thu nhập thấp có nhiều mối lo lắng đặc biệt là về kinh tế gia đình khiến họ có tâm lý bất ổn, dễ gặp phải những rối loạn trầm cảm. Giống như trong nghiên cứu tại Sông Cầu, tỷ lệ trầm cảm trong nhóm đối tượng không nghề nghiệp chiếm tỷ lệ cao nhất với 18,1\% [2]. Ngoài ra, chúng tôi cũng ghi nhận tỷ lệ trầm cảm cao ở nhóm người bệnh là cán bộ công chức, viên chức với $80 \%$, học sinh/sinh viên là $100 \%$, những người này đa phần giữ kín tình trạng nhiễm của mình với gia đình và xã hội, họ lo sợ ảnh hưởng tới công việc của mình, đặc biệt là khi họ là những cán bộ nhà nước, điều này dẫn tới tâm lý lo lắng, cảm giác thất bại của họ khiến tình trạng trầm cảm có thể xuất hiện. Mặt khác nhóm người bệnh đang làm công chức hay viên chức cũng chiếm số lượng ít, cỡ mẫu nhỏ có thể dẫn tới sự sai lệch về tỷ lệ này. Sự khác biệt về tình trạng trâm cảm giữa các nhóm nghề nghiệp hay giữa các nhóm thu nhập đều là sự khác biệt có ý nghĩa thống kê.

Trong số 140 bệnh nhân có dấu hiệu trầm cảm, có $17,9 \%$ người bệnh có hành vi sử dụng ma túy bao gồm cả điều trị nghiện các chất dạng thuốc phiện bằng methadone. Hầu hết các nghiên cứu trước đây chưa ghi nhận về sự khác biệt về tình trạng trầm cảm giữa 2 nhóm bệnh nhân có sử dụng và không sứ dụng ma túy. Có thể do lo ngại việc khai thác thông tin từ đối tượng về việc sử dụng các chất gây nghiện sẽ ảnh hưởng đến sự hợp tác của người bệnh, cũng như sự sai lệch thông tin về kết quả nghiên cứu.
Trong nghiên cứu này chúng tôi đã vẫn dụng tối đa những kỹ năng về phỏng vấn, sự tin tưởng của bệnh nhân đối với cán bô y tế - đa phần là những người đã chăm sóc, hố trợ và điều trị cho bệnh nhân trong thời gian dài, cũng như đảm bảo tính bí mật về thông tin khai báo của bệnh nhân. Kết quả cho thấy có sự khác biệt có ý nghĩa thống kê về tình trạng trầm cảm giữa những bệnh nhân có sử dụng ma túy và không sử dụng bất kỳ loại ma túy nào. Tuy nhiên cũng không thể loại trừ còn số ít trường hợp chưa khai báo thật sự trung thực về thông tin này.

Với yếu tố đường lây truyền, tỷ lệ trầm cảm trong các nhóm chia theo đường lây cũng tương đương giữa các nhóm với 37,5\% ở người bệnh lây qua đường máu, $36,9 \%$ ở người lây qua đường tình dục và $31,6 \%$ ở nhũng người không rõ đường lây. Tuy nhiên sự khác biệt về tình trạng trầm cảm giữa các nhóm bệnh nhân chia theo đường lây nhiễm HIV này cũng không có ý nghĩa thống kê.

\section{KẾT LUẦN}

Tỷ lệ trầm cảm ở người bệnh điều trị ARV là $36,3 \%$. Người bệnh nam có tỷ lệ trầm cảm thấp hơn người bệnh nữ $(35,5 \%$ và $37,3 \%, p>0,05)$, nhóm tuổi có tỷ lệ trầm cảm cao nhất là từ 50 tuổi trở lên $(75,4 \%)$, tỷ lệ thấp nhất ở nhóm 30 39 tuổi chiếm $18,6 \%$. Trong số những người bệnh ARV 82,8\% người thất nghiệp; $65,8 \%$ nông dẩn; $26,1 \%$ người làm lao động tự do có dấu hiệu trầm cảm. $72,3 \%$ có thu nhập dưới 1 triệu; $59,5 \%$ những người sử dụng ma túy có dấu hiệu trầm cảm.

\section{TÀI LIẸU THAM KHẢO}

1. BMj Publishing Group (2018), Tổng quan về HIV, BMJ Best Practice.

2. Nguyê̂n Thanh Cao (2012), Thực trạng trâm cảm và một số yếu tố nguy cơ đến trầm cảm ở người trưởing thành tại Phường Sông Câu, thị xã Bắc Kạn năm 2011 và đề xuất một số giải pháp, Bộ Y tế, Đ̇ại học Y dược Thái Nguyên.

3. Trương Thị Hòa (2018), Rối loạn trâm cảm trên người nhiếm HIV/AIDS ớ phòng khám ngoại trú huyêen Hóc Môn tại Thành phố Hồ Chí Minh, Viện hàn îâm khoa học quốc gia, Hoc viện khoa học xã hội.

4. Nguyê̂n Mạnh Hoan và Cao Ngọc Thành (2017), "Sàng loc trâm cảm sau sinh ở phụ nữ nhiếm HIV tại Việt Nam", Tạp chí Phụ Sản. 15(3), pp. 100-108.

5. Phạm Đình Quyết, võ Thị Duyên, Huỳnh Ngọc Vân Anh (2018), "Trầm cảm và các yếu tố liên quan ở ngưới nhiếm HIV/AIDS đang điều trị ARV", Tạp chí Y học thành phố Hồ Chí Minh. 22(1), pp. 285-292.

6. C. A. Esposito, Steel, Z., Gioi, T. M.,, T. T. Huyen va D Tarantola (2009), "The Prevalence of Depression Among Men Living With HIV 
Infection in Vietnam", Am J Public Health. 99(2), pp. 439-444.

7. Kimberly Green và các cộng sự (2010), "Integrating Palliative Care Into HIV Outpatient Clinical Settings: Preliminary Findings From an Intervention Study in Vietnam", Journal of Pain and Symptom Management. 40(1), pp. 31-34.

8. Maria Giulia Nanni và các cộng sự (2015), "Depression in HIV infected patients: a review",
Current psychiatry reports. 17(1), pp. 530.

9. Jacob K Saravanan B, Jonhson $S$, et al (2007), "Belief models in first episode schizophrenia in South India", Social psychiatry and psychiatric epidemiology. 42(6), pp. 446-451.

10. Cohen N. L Srinivasan J, Parikh S. V. (2003), "Patient attitudes regarding causes of depression: implications for psychoeducation", Canadian Journal of Psychiatry. 48(7), pp. 493-495.

\section{ĐÁNH GIÁ CHẤT LƯợNG CUộC SỐNG BẰNG THANG ĐIỂM HEARTQOL CHO BÊ̂NH NHÂN CAN THIỆP ĐộNG MACH QUA DA}

\section{TÓM TẮT}

Mục tiêu: Xác định đặc điểm và một số yếu tố liên quan đến chất lượng sống của người bệnh sau can thiệp động mạch vành (ĐMV) qua da bằng thang điểm HeartQ̉oL taii Bệnh Viện Tim Hà Nội. Đối tượng và phương pháp: mô tả tiến cứu theo dõi dọc 150 người bệnh can thiệp ĐMV qua da tại Bệnh Viện Tim Hà Nội từ $1 / 6 / 2020$ đến 28/2/2021, sử dụng thang điểm HeartQoL để đánh giá chất lượng cuộc sống (CLCS) tại các thời điểm nghiên cứu. Kết quả: Tuổi trung bình là $63.7 \pm 10$ tuổi. Tỉ lệ giới nam (66.7\%). Điểm trung bình CLCS theo thang điểm HeartQoL tại các thời điểm sau can thiêp (từ $2.1 \pm 0.4$ đến $2.5 \pm$ 0.3) cao hơn, có sự khác biệt so với trước can thiệp $(1.9 \pm 0.5) p<0.001$. Điểm CLCS thuộc lĩnh vực thể chất $(1.9 \pm 0.4$ đến $2.4 \pm 0.4) p<0.05$, điểm thuộc lĩnh vức cảm xúc $(2.7 \pm 0.4$ đến $2.8 \pm 0.3)$ cao hởn lĩnh vực thể chất và cải thiện theo thời gian $p<0.05$. Còn đ̛̉au ngực sau can thiệp ảnh hưởng đến chất lượng cuộc của người bệnh. Tình trạng suy tim khó thở theo NYHA có điểm CLCS thấp hơn bệnh nhân không có triệu chứng, nữ giới thấp hơn nam giới. Tuổi $<60$ tuổi, bệnh nhân có trình độ học vấn cao có điểm CLCS cao hởn $(p<0,05)$. Kết luận: CLCS của người bênh tốt nhất sau sáu tháng can thiệp ĐMV qua da. Các yễu tố ảnh hưởng đến CLCS bao gồm: giới tính, trình độ học vân, nhóm tuổi, còn tình trạng đau ngực và suy tim sau can thiêp.

Tư khóa: Chất lượng cuộc sống, HeartQoL, can thiệp động mạch vành qua da

\section{SUMMARY \\ ASSESSMENT OF THE QUALITY OF LIFE IN PATIENTS AFTER PERCUTANEOUS CORONARY INTERVENTION BY THE HEARTQOL SCALE \\ Objectives: The goal of the study was investigated the quality of life for patients after Percutaneous Coronary Intervention (PCI) by HeartQol questionnaire.}

*Bệnh viện Tim Hà Nội

Chịu trách nhiệm chính: Phan Thị May

Email: maypt.vthn@gmail.com

Ngày nhận bài: 28.6.2021

Ngày phản biện khoa học: 23.8.2021

Ngày duyệt bài: 30.8.2021

\section{Phan Thị May*, Phạm Như Hùng* và cs.}

Methods \& Results: From June 2020 to February 2021, we prospectively enrolled 150 patients after percutaneous coronary intervention, aged $63.7 \pm 10.3$ years $(66,7 \%$ male) were measured by HeartQoL score. The average score of overall quality of life after PCI is singnificantly improved before intervention $(2.1 \pm 0.4$ to $2.5 \pm 0.3 ; p<0.001)$. Quality of life score in the physical domain aspects singnificantly improves from $1.9 \pm 0.4$ before PCI to $2.4 \pm 0.4$ after PCI $(p<0.05)$. The sex characteristics, education level, age, chest pain after PCI and NYHA are related to the quality of life of patients after PCI $(p<0.05)$. Conclusion : Our study shows that the majority of patients had improved quality of life after six months of PCI. Sex characteristics, education level, age, chest pain after PCI and NYHA are related to the quality of life of patients.

Keywords: HeartQol, Percutaneous Coronary Intervention, Cardiovascular

\section{I. ĐĂT VẤN ĐỀ}

Cùng với sự phát triển kinh tế xã hội, vấn đề CLCS được quan tâm nhiều hơn. Hiện nay, xu thế chăm sóc và điêu trị chung trền thế giới không chỉ giải quyết vấn đề về bệnh lý mạch vành mà cần quan tâm giải quyết tổng thể các yếu tố tác động, ảnh hưởng lên chất lượng sống của người bệnh. Hiện nay có khá nhiểu thang điểm, bộ công cụ đánh giá CLCS như bộ câu hỏi SF-36, Macnew, Seattle Angina, thang điểm HeartQoL. Bộ câu hỏi HeartQoL đánh giá mức độ ảnh hưởng của bệnh lý mạch vành sau can thiệp lên các lĩnh vực hoạt động thể chất, lĩnh vực cảm xúc của người bệnh. Đánh giá CLCS của người bệnh sau can thiệp ĐMV qua da là cân thiết, quan trọng, qua đó giúp nhân viên y tế có cách nhìn tồng quát hơn, giúp người bệnh có CLCS tốt hơn cả về thể chất lấn tinh thân. Tại Việt Nam, việc sử dụng thang điểm HeartQoL để đánh giá CLCS của người bệnh sau can thiệp ĐMV qua da chưa được áp dụng. Vì vậy, chúng tôi tiến hành nghiên cứu đề tài này với hai mục tiêu là xác định đặc điểm CLCS ở người bệnh sau can thiệp 